\title{
IoT and Cloud Computing Issues, Challenges and Opportunities: A Review
}

\author{
https://doi.org/10.48161/qaj.v1n2a36
}

\author{
$1^{\text {st }}$ Nasiba M. Abdulkareem \\ Master Student \\ Duhok Polytechnic University \\ Duhok, Iraq \\ Nasiba.mahdi@dpu.edu.krd
}

\author{
$4^{\text {th }}$ Dindar Mikaeel Ahmed \\ IT Dept. \\ Duhok Polytechnic University \\ Duhok, Iraq \\ dindar.ahmed@dpu.edu.krd
}

\author{
$2^{\text {nd }}$ Subhi R. M. Zeebaree \\ IT Dept. \\ Duhok Polytechnic University \\ Duhok, Iraq \\ Subhi.rafeeq@dpu.edu.krd \\ $5^{\text {th }}$ Ahmed Saifullah Sami \\ Information Technology Department \\ Duhok Polytechnic University \\ Duhok, Iraq \\ ahmed.saifullah@dpu.edu.krd
}

\author{
$3^{\text {rd }}$ Mohammed A. M.Sadeeq \\ Quality Assurance \\ Duhok Polytechnic University \\ Duhok, Iraq \\ mohammed.abdulrazaq@dpu.edu.krd \\ $6^{\text {th }}$ Rizgar R Zebari \\ Research and Development Center \\ Nawroz University \\ Duhok, Iraq \\ rzgarz11@gmail.com
}

\begin{abstract}
With the exponential growth of the Industrial Internet of Things (IIoT), multiple outlets constantly produce a vast volume of data. It is unwise to locally store all the raw data in the IIoT devices since the end devices' energy, and storage spaces are strictly constrained by Selforganization and microorganisms. IoT networks enable outsourced data collection and cloud storage irrespective of the resource-constrained nature of the IoT. For the next segment of observations, there is a sequence of unfamiliar safeguards for IoT and cloud integration problems. Cloud computing delivery is highly efficient, storage is becoming more and more current, and some groups are now altering their data from in-house records Cloud Computing Vendors' hubs. Intensive IoT applications for workloads and data are subject to challenges while utilizing cloud computing tools. In this paper, we research IoT and cloud computing and address cloud-compatible problems and computing techniques to promote IoT programs' stable transition to the Cloud.
\end{abstract}

Keywords - Internet of Things, IoT, Cloud Computing, Security, IoT-cloud.

\section{INTRODUCTION}

The Internet of Things (IoT) allows user to link billions of Intelligent Machines and to exchange information, monitoring, and control for services such as home automation systems, linked with each other, health care, Agriculture, security surveillance, power grid, or critical infrastructure control and control the IoT is the next contemporary approach [1]. in which the borders between artificial and actual environments are continually being reduced by dynamic digitalization of physical systems ready to deliver value-added services for mobile devices [2]. The IoT is run by purpose-built software, which can do so by Feeling, controlling, and changing the state of things
[3]. This life-saving invention must become a series of connected objects in an interconnected world, allowing surgeons to conduct remote procedures and people and evaluate their homes and power providers. Lead the infrastructure with reasonable efficiency and a critical national situation - security program $[4,5]$. Due to the multiplicity of IoT usage technology, there was a sharp increase in proliferation from smart devices connected to the (IoT) and expected to reach more from 20.4 billion by the end of $2020[6,7]$. With the increasing items of heterogeneous devices linked to the IoT and data generation, it will be very difficult for the independent IoT to apply power and bandwidth for tasks efficiently[8]. In this opinion, the integration of cloud computing and the IoT was conceived [9]. When the Cloud is linked to the IoT, a situation creates multimedia content [10]. Since multimedia value consumes more processing capacity, space, storage, and resource scheduling, it will be critical to manage it effectively and perform effective cloud resource management. Otherwise, IoT services with critical tasks require highly responsive and processing[11]. In this case, the user cannot communicate through the Cloud range over the Internet [12].

The public Cloud and the IoT are two separate yet strong systems integrated to become an important part of the Internet's future [13]. These integrations are seen as a huge subversive process with large-scale benefits in the future [14]. Much change is being made in the IoT and the Cloud. The challenges addressed during the investigation into integrating the IoT with Cloud Computing have shown inconclusive results [15]. So, in his cloud-IoT research paper Architecture, identifying cloud-IoT problems and emphasized our study of security challenges. For our analysis, the search questions are as follows: 
1. What is the need for the IoT to be integrated with cloud computing?

2. Will the integration of the IoT with the Cloud present any challenges?

This paper's critical contribution is to widen current literature by exploring the possibilities and challenges of applying IoT and cloud computing and addressing cloudcompatible problems and computing techniques to promote IoT programs' stable transition to the Cloud.

The paper structure: have the background theory in Section II, Cloud-IoT challenges In Section III, Literature Review in Section IV, Results and discussion in section V, Finally, the conclusion in section VI.

\section{BACKGROUND}

Cloud Computing services are implemented in many areas relevant to the IoT, including Genomics Data Processing, Teaching, and Studying, Services for Small and Medium Businesses, E-Learning Method, Augmented Reality, Manufacturing, Emergency Recovery, Smart Cities and others, Remote Forensics, Hospitality Business, E-Government and Human Resource Administration, Internet of Cars[16, 17]. Challenges in cloud computing and the IoT separately and in Application environments that are unique[18]. Critical difficulties in researching how the IoT and Cloud Computing could be integrated yielded inconclusive findings.

Cloud computing and IoT have spread globally and expanded quickly in recent years [19]. The characteristics they show can be outstanding when combined. They are each really special and important for each other [20]. Researchers scheduled a range of applications concerning Coordination of Cloud and IoT to develop and accumulate data as it gets assistance from cloud storage and computational capability. In this part, then explain the Cloud-IoT (Cloud and IoT) architecture. The layers of knowledge in Fig 1 are explained below. The application, network, and sensing layers are interconnected.

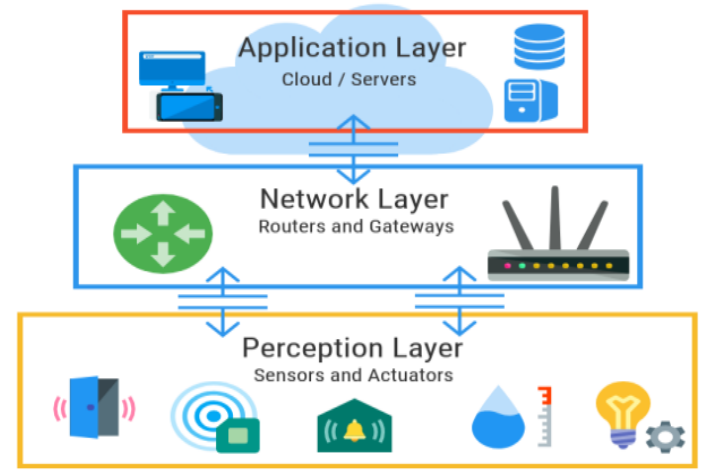

Fig. 1. Cloud-IoT Architecture

Objects capable of reading and collecting data via various IoT systems are exhibited through IoT visualization protocols. For easier processing, this knowledge may be processed in the Cloud [21]. The application layer can sense environment data and send requests to the Cloud simultaneously to process and obtain sensor information results [22]. It is also necessary to also repost information to the IoT and other IoT objects, data obtained from the sensor layer, and data analysis for additional processing [23, 24].

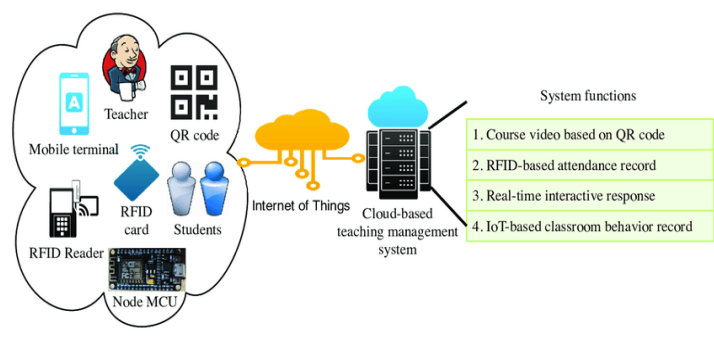

Fig. 2. Cloud-IoT Environment

RESTful with Web servers and Simple Object Access Protocol (SOAP) is used for interacting between devices on the Internet. SOAP Web Services works with XML sharing, but most WSS works with an HTTP protocol essential for energy-limited resources and computers as shown in Fig 2 [25]. The Constrained Application Protocol (CoAP) program protocol requires using RESTful facilities by computers with minimal resources. For wireless communication between devices with limited resource access [26]. CoAP uses the UDP protocol instead of TCP, which is widely used in HTTP.

\section{CLOUD-IOT CHALLENGES}

A middle layer between objects and applications is Cloud Storage, which conceals nuances and functions. We all recognize that the IoT is a network of linked artifacts, and various apps are involved in these objects [27]. The issues are unique for each application, but they typically fall into a similar category. To resolve these challenges, it must focus more primarily on security challenges and evaluate the consequences of the new techniques [28]. After integrating the Cloud and the IoT, there have been continuing concerns about the cloud provider's mistrust and understanding of the physical location of the details transmitted to the Cloud via different IoT agreements [29]. There are several concerns about the multi-tenant cloud service storage system. Multiple consumer information is housed in a single facility, which can undermine confidentiality and the course of confidential information leakage [30]. Due to Cloud services provider distrust, this form of vulnerability is considered an insider threat and is one of the IT industry's most unforeseen issues to date. The critical challenges of Cloud-IoT explained as follows [31].

\section{A. Security}

Data from IoT was placed in the Cloud for processing and retrieval. The involves encryption of data sent to or saved in cloud-based repositories and data security during cloud access and use. [32, 33]. The degree to which there is a lack of cloud computing information is such that data owners do not understand their own data's physical position. Today, data is related to all around us, so data security in the Cloud-IoT paradigm is the main topic [34].

\section{B. Storage and Computational performance}

Plans that include the use of cloud-based IoT devices require a high degree of performance goal requirements. Such specifications can be difficult to meet in all settings 
because cloud-based IoT devices are in motion for many applications [35].

\section{Reliability}

The IoT devices are dependent on the Cloud to work providers for time-critical apps, and the effect would directly reflect the program's output. In cars, surgical instruments, or in the security field, for example [36].

\section{Big Data Storage}

Nearly 50 billion IoT devices will be offered by about 2025 , and that revenue will be a big obstacle for cloud service providers to rapidly have fast and safe access to data [37].

\section{E. Maintenance}

Depending on the learned in the above segment, extremely efficient techniques and plans are needed to track and manage protection and efficiency in the cloud environment to fulfill the requirements of as high as 50 billion IoT devices [38].

\section{F. Edge computing}

Latency limitations, mobility-bound, and Geodistributed IoT implementations request the Cloud's immediate answer. Therefore, edge computing is a compromise between classic computing and cloud computing, albeit closer to the implementations but difficult to incorporate because it needs position awareness $[39,40]$.

\section{G. User aided IoT devices}

In such IoT implementations, users are expected to include details and benefits to be compensated for their exchange participation. The daunting challenge since the social factors come into action, where the consumer from his/her context contributes [41].

\section{H. Interaction with device}

Cloud-IoT systems often need input from a wide range of devices to be processed and implemented. In this situation, specifications such as storage space and cloudbased computing capacity can get tough [38]

\section{LITERATURE REVIEW}

Regarding IoT and cloud computing, they are on two different continents. However, their properties are combined, which is why convergence is advantageous to both.

Mohiuddin, Irfan, et al. [30] discussed the problems surrounding storage units in data centers. A special classification method to ensure loads are equally dispersed during allocation, and our key contribution is on the VMbased migration approach. The VM migration is intended to consolidate the VMs depending on the workload, reduce the use of resources, and encourage green computing. As such, we should call the approach Workload Aware Virtual Machine Consolidation Method (WAVMCM). The author also verifies the proposed method by contrasting it with an AI-dependent probabilistic method, including Simulated Annealing, Genetic Algorithm, and an experiment to compare the roaming rates between cells. Experiments show that WAVMCM reduces the number of operating servers by $9 \%$, saving $15 \%$ of the CPU's electrical consumption than genetic algorithm-based approaches.

Zhang, Wei-Zhe, et al. [42] recommended a Joint Load Balancing and Mobile Edge Computing (MEC) Offloading Strategy, adding a new security layer to mitigate possible security problems. Next, a load-balancing algorithm is proposed to redistribute sBS mobile device users (MDUs) effectively. Besides, a new advanced encryption standard (AES) cryptographic technology is presented as a protection layer for safeguarding data vulnerability during transmission with an electrocardiogram (ECG) signalbased encryption and decryption. An optimized model for load balance, measurement offloading, and protection is often conceived as a concern to reduce the system's time and energy requirements. Detailed experimental findings show that, compared with local executions, our machine consumption with and without the additional safety levels will save some $68,2 \%$ and $72,4 \%$.

Riad, Khaled, et al. [43] The Multi-Dimensional Access Control (MD-AC) software to allow and remove users in the Cloud dynamically through various authorities has been adopted. The experimental findings demonstrate that MD-AC will determine requests for access in a reasonable and appropriate period. The average encryption and decryption times are 18 and $10 \mathrm{~ms}$, respectively, despite very complicated laboratory conditions and multiple transactions. The proposed scheme is also tested and contrasted with state-of-the-art schemes in recent years. The findings show that the proposed regime against numerous well-known attacks is fast and stable. Also, MD$\mathrm{AC}$ can be used to protect IoT services' privacy in the cloud world.

Mallikarjuna, Betty, et al. [44] suggested feedback output based on a Fuzzy algorithm verified with the two separate settings such as iFogSim tool kit simulations and MATLAB R2017b optimized scheduling. Applications from the server-side, displayed by the MATLAB Fuzzy toolkit, and tested the intended model have been presented by the fuzzy-based scheduling architecture that has generated client ratings of VMM. Rather than providing a toolkit for iFogSim that improves relocation of tasks and device scalability. The algorithm output in MATLAB R2017b has been tested using tens of thousands of casually generated sets of work on the fluid inference method, generating VM ratings and total accuracy of 36.23 percent. The best results are for 'Excellent' being threatened with an accuracy of $54.55 \%$. The worst results are $20 \%$ for 'Bad.' Fog computing is the answer to IoT-powered data mining in the Cloud process data effectively. Edge computing is the key. iFogSim has tested the suggested approach. The approach compares and proves the actual scheduling process, verifying and updating the QoS parameters using current dynamic algorithms.

Anuradha, et al. [45] Provides a framework to boost the health industry's current success internationally. The conventional medical constraints can be solved as all medical records have to be kept in the Cloud. Encryption is done using the AES algorithm to guarantee the security and confidentiality of cancer patients. The emphasis is on conveniently managing health data for people away from their hometown, as the requisite cancer therapy is housed 
in the Cloud. The time it takes for the mission to complete is decreased by VMs from 400 to 160 . CloudSim offers a modular simulation structure to display and repeat outcomes.

Aburukba, Raafat, et al. [46] Take IoT Service Request scheduling as a problem for optimization by integer programming to reduce the overall delay in demand. The preparation problem is NP-hard in nature, and thus exact optimization solutions to large-size problems are insufficient. This paper proposes a targeted application of the genetic algorithm (GA) as a heuristic approach to planning IoT requests to reduce overall latency. The GA is tested in an environment of simulation, which considers the complex nature of the environment. GA's performance is measured and contrasted with waited-fair queuing (WFQ) performance, goals tight queuing (PSQ), and round-robin (RR) strategies. The findings indicate that the general latency is 21.9 percent to $46.6 \%$ higher than most algorithms for the suggested solution. The solution proposed also shows a substantial increase of up to 31 percent in the execution of request deadlines.

Ali, Babar, et al. [47] suggested the Volunteer Assisted Fog Computing (VSFC) design examines the interplay of these two modern distributed computing realms. Through this, we could reduce inherent transmission delays of cloud computing while reducing energy consumption while also reducing the need for network usage. In order to this effect, the iFogSim toolkit supports a broader range of fogging scenarios. Extremities calculations demonstrate that VSFC beats conventional FC-cloud calculators by reducing the time limit by $47.5 \%, 93 \%$, and $92 \%$ in normal to extreme loads.

Wang, Mingzhe, et al. [48] propose an optimization algorithm for access to IoT data in cloud computing. The article describes the increased stability of data transfer over a wireless network, which improves technical assistance in handling and managing data. The model simulates the experimental results and will be run in OPNET Modeler. Furthermore, the experimental findings reveal that the optimized IoT data is more effective in transmission speed, machine resource occupation, and response time. Furthermore, the IoT's optimized transmission performance is 99 percent, while the average fault tolerance score of optimized algorithms is 96.12 percent.

Fuentes, Henry, et al. [49] The leak detection algorithm is suggested based on rules, historical context, and user position that can manage to detect ten different forms of ingestion, such as normal, low, extreme, and anomalous. A smart meter is used to collect data, which is then sent to a local server for analysis, analyzed, and sent to the Cloud for algorithms to be viewed on the Internet. The findings reveal that the algorithm has $100 \%$ accuracy, memory, precision, and f1 score to detect leakage, much better than other methods, and has a margin of error of $4.63 \%$ in calculating water usage.

Abdel-Basset et al. [50] suggested a novel IoT device for identifying and tracking patients with type- 2 diabetes. The WBAN collects data on a user's social interactions and how emotions and other physiological changes occur. The main groups of the data we collected were Type- 2 diabetes and uninfected individuals. A hybrid technique based on both neuromorphic VIKOR type-2 was suggested in this study to improve the estimation of the risk of type-2 diabetes. Consequently, we may predict a decision support framework to predict type-2 diabetes risks for patients accurately with the study's findings. If the user is deemed "diseased", the algorithm will intelligently select the step, form, and treatment. Our intelligent algorithms can help minimize medication execution time by $9.8 \%$ and improve patient recovery rates in serious health conditions.

Mavromatis, Alex, et al. [51] plan, analyze, and validate a novel Software-Defined IoT Management (SDIM) system for management on an interconnected sensor network. (SDIM) is optimized for edge-edge Wireless Sensor Networks (WSNs) deployments, targeting dense IoT deployments where centralized system management cannot scale well for Cloud-based WSNs. Nevertheless, SDIM can be used for cloud-based tracking and control of all IoT domains thanks to our introduced Software-Defined Networking (SDN) Topology Aggregation (SDTA). Based on efficiency measurements such as the time required to provide multi-access edge computing (MEC) nodes, the author demonstrates that SDIM executes such cutting-edge IoT management schemes on both large-scale emulated IoT networks and field trials. Relevant SDIM will decrease average provisioning times by $60-80 \%$ compared to NETCONF Light and 46-60.3\% compared to LWM2M.

Ding, Li Wang, et al. [52] The heterogeneously integrated network control algorithms are studied. The advantages of ISA technology are used to capture and extract all of the resources in a heterogeneous integrated network. Moreover, in the resource management algorithm, a resource management model is developed, and an optimized heterogeneous network device-specific calculation will be done to construct the paper. Data on pest and disease control were collected and coded. A resource management algorithm can reduce errors due to the loss of information that the secure transmission of information eliminates. Despite an algorithm error of $20 \%$, Safety efficiency is above 90 percent (sensitivity). Therefore, the proposed algorithm will considerably increase the management of converged heterogeneous networks and reduce resource management errors, reducing resource management costs and improving the reliability with which they are implemented.

Debauche, Olivier, et al. [53] defined a new Edge artificial intelligence of thing architecture through a partnership deployed in the Cloud with microservices. Besides the use or deployment of advanced AI algorithms. The proposed architecture was analyzed using nontraditional AI techniques and models trained on the P100powered cloud server. Statistical analysis was then conducted on the initial model's output (inference time) and accuracy with a test data collection of 443 images. The experiment revealed that the Jetson Nano is slower than the Tesla P100, and the accuracy decreases by around 5\%.

Chen, Jienan, et al. [54] proposed an intelligent Resource Allocation Framework (iRAF), The Collaborative Mobile Edge Computing (CoMEC) network's Architecture for Resource Allotment Problems. The iRAF algorithm's core is a profound strengthening learning algorithm for allocating domain resources using multiple network states and functional features such as edge server and device computing power, communication 
channel performance, resource utilization, and the latency of services requirements. The proposed IRAF will automatically learn the network environment, delegate resources, and improve latency and electricity usage efficiency by practicing. iRAF becomes a trainer of its own: the Deep Neural Network (DNN) is learned to selfsupervised predict iRAF's resource allocation operation. The training data come from the Monte Carlo Tree Search (MCTS) procedure. The potential of MCTS to simulate paths into the future is a huge asset. It derives the best action from a reward mechanism, starting with a root state. Via our tests, iRAF would achieve $59.27 \%$ and $51.71 \%$ better outcomes than the gulf quest and the profound QLearning algorithms.

Abbasi, Mahdi, et al. [55] There are two methods focused on XCS learning classifier system (LCS), XCS and BCM-XCS, through which network power can be controlled, and workload processing latency can be reduced. Our experiment shows that BCM-XCS is more successful than the basic XCS process. The suggested approaches spread the workloads to reduce the delay associated with processing information and between the process and cloud nodes. In addition to the benefits of minimizing the fluctuation of the delay, the moderate resource usage at the edge of the network, the suggested strategies would reduce the processing time by $42 \%$. In tandem with the network edges, the proposed methods can also charge recycled batteries $18 \%$ faster than the optimal procedure.

\section{RESULTS AND DISCUSSION}

From the previous section, it can be seen that researchers have employed different types of techniques and tools to get better accuracy and performance. Scientists have issued a list of their recommendations upon studying theirs. Table 1 of the paper explains the explanations explained in the paper. The project should include comparing the success and commonalities in the methodology of using IoT with Cloud computing. The researcher used Tools and Technique and the Significant Satisfied Aims approach to analyze the results. Besides, the precise and efficient proposed method and framework.

It is evident from the table that some researchers depending on the VM migration technique, AES, ECG technology, MATLAB Fuzzy toolbox, MATLAB R2017b. Rather than the genetic algorithm, round-robin techniques, iFogSim toolkit to reach the Significant Satisfied Aims. Another method is used, such as Multi-domain IoT Architecture, IoT Management Protocols, Heterogeneous integrated network resource collection. Also, some researchers use Resource management algorithm modeling, the deep Q-learning based algorithms, Deep Neural Network, Monte Carlo Tree Search algorithm, XCS learning classifier architecture, BCM-XCS.

By using this methodology and techniques, both researchers have strong structures, frames, and functions such as a new method for live VM migration, Workload Aware Virtual Machine Consolidation Method (WAVMCM), a Joint Load Balancing and Mobile Edge Computing (MEC) Offloading Strategy, feedback output based on a Fuzzy algorithm, Fog Computing Allowed Volunteer (VSFC), a novel IoT device for identifying and tracking patients with type-2 diabetes, novel Software-
Defined IoT Management (SDIM) system for management on an interconnected sensor network. The best accuracy and efficiency have been enhanced by predicted algorithms such as a $9 \%$ reduction in operation Servers, a savings of $15 \%$ on power consumption, $59,27 \%$, and $51,71 \%$ acceleration on the service latency, and overall fault tolerance score of $96,12 \%$. In comparison, the security performance remains above $20 \%$.

TABLE I. Cloud COMPUTING With IOT DEVISES Review

\begin{tabular}{|c|c|c|c|}
\hline RESEARCHER & $\begin{array}{l}\text { TOOLS AND } \\
\text { TECHNIQUE } \\
\text { USED }\end{array}$ & $\begin{array}{l}\text { SIGNIFICANT } \\
\text { SATISFIED AIMS }\end{array}$ & $\begin{array}{l}\text { ACCURACY } \\
\text { AND } \\
\text { PERFORMANCE }\end{array}$ \\
\hline $\begin{array}{l}\text { MOHIUDDIN, } \\
\text { IRFAN, ET AL. } \\
{[30]}\end{array}$ & $\begin{array}{l}\text { VM } \\
\text { MIGRATION } \\
\text { TECHNIQUE, }\end{array}$ & $\begin{array}{l}\text { PROPOSE A NEW } \\
\text { METHOD FOR LIVE } \\
\text { VM MIGRATION, } \\
\text { WORKLOAD } \\
\text { AWARE VIRTUAL } \\
\text { MACHINE } \\
\text { CONSOLIDATION } \\
\text { METHOD } \\
\text { (WAVMCM) }\end{array}$ & $\begin{array}{l}\text { REDUCES } 9 \% \\
\text { OF OPERATING } \\
\text { SERVERS, } \\
\text { SAVING ABOUT } \\
15 \% \text { OF POWER } \\
\text { USAGE. }\end{array}$ \\
\hline $\begin{array}{l}\text { ZHANG, } \\
\text { WEIZHE, ET } \\
\text { AL. [42] }\end{array}$ & $\begin{array}{l}\text { AES, ECG } \\
\text { TECHNOLOGY }\end{array}$ & $\begin{array}{l}\text { RECOMMENDED A } \\
\text { JOINT LOAD } \\
\text { BALANCING AND } \\
\text { MOBILE EDGE } \\
\text { COMPUTING } \\
\text { (MEC) } \\
\text { OFFLOADING } \\
\text { STRATEGY. }\end{array}$ & $\begin{array}{l}\text { MACHINE } \\
\text { CONSUMPTION } \\
\text { WILL SAVE } \\
68,2 \% \text { AND } \\
72,4 \% \text {. }\end{array}$ \\
\hline $\begin{array}{l}\text { RIAD, } \\
\text { KHALED, ET } \\
\text { AL. [43] }\end{array}$ & $\begin{array}{l}\text { NOTARIZATIO } \\
\mathrm{N} \\
\text { ALGORITHMS }\end{array}$ & $\begin{array}{l}\text { ADOPTED THE } \\
\text { MULTI- } \\
\text { DIMENSIONAL } \\
\text { ACCESS CONTROL } \\
\text { (MD-AC) } \\
\text { SOFTWARE. }\end{array}$ & $\begin{array}{l}\text { THE AVERAGE } \\
\text { ENCRYPTION } \\
\text { AND } \\
\text { DECRYPTION } \\
\text { TIMES ARE } 18 \\
\text { AND 10MS, } \\
\text { RESPECTIVELY }\end{array}$ \\
\hline $\begin{array}{l}\text { MALLIKARJU } \\
\text { NA, } \\
\text { BASETTY, ET } \\
\text { AL. [44] }\end{array}$ & $\begin{array}{l}\text { MATLAB } \\
\text { FUZZY } \\
\text { TOOLBOX, } \\
\text { MATLAB } \\
\text { R2017B }\end{array}$ & $\begin{array}{l}\text { SUGGESTED } \\
\text { FEEDBACK } \\
\text { OUTPUT BASED ON } \\
\text { A FUZZY } \\
\text { ALGORITHM }\end{array}$ & $\begin{array}{l}\text { GENERATING } \\
\text { VM RATINGS } \\
\text { AND TOTAL } \\
\text { ACCURACY OF } \\
36.23 \text { PERCENT. }\end{array}$ \\
\hline $\begin{array}{l}\text { ANURADHA } \\
\text { ET AL. [45] }\end{array}$ & $\begin{array}{l}\text { AES } \\
\text { ALGORITHM }\end{array}$ & $\begin{array}{l}\text { PROVIDES A } \\
\text { FRAMEWORK TO } \\
\text { BOOST THE } \\
\text { HEALTH } \\
\text { INDUSTRY'S } \\
\text { CURRENT SUCCESS } \\
\text { INTERNATIONALL } \\
\text { Y }\end{array}$ & $\begin{array}{l}\text { VMS } \\
\text { DESCRIBES } \\
\text { THE TIME OF } \\
\text { THE } \\
\text { MISSISSIUM } \\
\text { FROM } 400 \text { TO } \\
160 . \\
\text { SUBSTANTIAL } \\
\text { BY VMS. }\end{array}$ \\
\hline $\begin{array}{l}\text { ABURUKBA, } \\
\text { RAAFAT ET } \\
\text { AL, ET AL. } \\
{[46]}\end{array}$ & $\begin{array}{l}\text { GENETIC } \\
\text { ALGORITHM, } \\
\text { ROUND-ROBIN } \\
\text { TECHNIQUES }\end{array}$ & $\begin{array}{l}\text { MODELED IOT } \\
\text { SERVICE REQUEST } \\
\text { SCHEDULE AS AN } \\
\text { ISSUE OF } \\
\text { OPTIMIZATION. }\end{array}$ & $\begin{array}{l}\text { OVERALL } \\
\text { LATENCY IN } \\
\text { THE } \\
\text { APPLICATION IS } \\
21.9 \% \text { TO } \\
46.6 \%\end{array}$ \\
\hline $\begin{array}{l}\text { ALI, BABAR, } \\
\text { ET AL. [47] }\end{array}$ & $\begin{array}{l}\text { FOG DEVICES, } \\
\text { IOT DEVICES, } \\
\text { IFOGSIM } \\
\text { TOOLKIT }\end{array}$ & $\begin{array}{l}\text { PROPOSED FOG } \\
\text { COMPUTING } \\
\text { ALLOWED } \\
\text { VOLUNTEER } \\
\text { (VSFC) }\end{array}$ & $\begin{array}{l}47.5 \% \text { LESS } \\
\text { LATENCY, 93\% } \\
\text { LESS ENERGY, } \\
\text { AND 92\% LESS } \\
\text { NETWORK } \\
\text { CONSUMPTION }\end{array}$ \\
\hline $\begin{array}{l}\text { WANG, } \\
\text { MINGZHE, ET } \\
\text { AL. }[48]\end{array}$ & $\begin{array}{l}\text { THE HASH } \\
\text { ALGORITHM, } \\
\text { HADOOP } \\
\text { DISTRIBUTED } \\
\text { FILE SYSTEM, }\end{array}$ & $\begin{array}{l}\text { SUGGESTED AN } \\
\text { OPTIMIZATION } \\
\text { ALGORITHM FOR } \\
\text { CLOUD STORAGE } \\
\text { BY IOT DATA } \\
\text { PROTECTION AND } \\
\text { SAVING. }\end{array}$ & $\begin{array}{l}\text { THE AVERAGE } \\
\text { FAULT } \\
\text { TOLERANCE } \\
\text { SCORE OF } \\
\text { OPTIMIZED } \\
\text { ALGORITHMS IS } \\
96.12 \text { PERCENT. }\end{array}$ \\
\hline $\begin{array}{l}\text { FUENTES, } \\
\text { HENRY, ET } \\
\text { AL. [49] }\end{array}$ & $\begin{array}{l}\text { LOCAL } \\
\text { SERVER } \\
\text { (GATEWAY), } \\
\text { NODEMCU } \\
\text { ESP8266 }\end{array}$ & $\begin{array}{l}\text { RECOMMENDED } \\
\text { THE LEAK } \\
\text { DETECTION } \\
\text { ALGORITHM. }\end{array}$ & $\begin{array}{l}\text { THE } \\
\text { ALGORITHM } \\
\text { HAS } 100 \% \\
\text { ACCURACY }\end{array}$ \\
\hline $\begin{array}{l}\text { ABDEL- } \\
\text { BASSET, ET } \\
\text { AL. }[50]\end{array}$ & $\begin{array}{l}\text { VIKOR } \\
\text { METHOD, } \\
\text { WBAN FOR } \\
\text { WIRELESS } \\
\text { TRANSMISSIO }\end{array}$ & $\begin{array}{l}\text { SUGGESTED A } \\
\text { NOVEL IOT } \\
\text { DEVICE FOR } \\
\text { IDENTIFYING AND } \\
\text { TRACKING }\end{array}$ & $\begin{array}{l}\text { MINIMIZE } \\
\text { MEDICATION } \\
\text { EXECUTION } \\
\text { TIME BY } 9.8 \%\end{array}$ \\
\hline
\end{tabular}




\begin{tabular}{|c|c|c|c|}
\hline & $\mathrm{N}$ & $\begin{array}{l}\text { PATIENTS WITH } \\
\text { TYPE-2 DIABETES. }\end{array}$ & \\
\hline $\begin{array}{l}\text { MAVROMATI } \\
\text { S, ALEX, ET } \\
\text { AL. [51] }\end{array}$ & $\begin{array}{l}\text { MULTI- } \\
\text { DOMAIN IOT } \\
\text { ARCHITECTUR } \\
\text { E, IOT } \\
\text { MANAGEMEN } \\
\text { T PROTOCOLS, } \\
\text { LWM2M, } \\
\text { AND } \\
\text { NETCONF } \\
\text { LIGHT }\end{array}$ & $\begin{array}{l}\text { PLAN, ANALYZE } \\
\text { AND VALIDATE A } \\
\text { NOVEL } \\
\text { SOFTWARE- } \\
\text { DEFINED IOT } \\
\text { MANAGEMENT } \\
\text { (SDIM) SYSTEM } \\
\text { FOR } \\
\text { MANAGEMENT ON } \\
\text { AN } \\
\text { INTERCONNECTED } \\
\text { SENSOR NETWORK. }\end{array}$ & $\begin{array}{l}\text { DECREASE } \\
\text { AVERAGE } \\
\text { PROVISIONING } \\
\text { TIMES BY 60- } \\
80 \%\end{array}$ \\
\hline $\begin{array}{l}\text { DING, LI } \\
\text { WANG, ET } \\
\text { AL. [52] }\end{array}$ & $\begin{array}{l}\text { HETEROGENE } \\
\text { OUS } \\
\text { INTEGRATED } \\
\text { NETWORK } \\
\text { RESOURCE } \\
\text { COLLECTION, } \\
\text { RESOURCE } \\
\text { MANAGEMENT } \\
\text { ALGORITHM } \\
\text { MODELING. }\end{array}$ & $\begin{array}{l}\text { THE } \\
\text { HETIOLOGICAL } \\
\text { RESOURCE } \\
\text { MANAGEMENT } \\
\text { ALGORITHMS } \\
\text { ARE ANALYZED } \\
\text { NETWORK } \\
\text { INTEGRATED }\end{array}$ & $\begin{array}{l}\text { DESPITE AN } \\
\text { ALGORITHM } \\
\text { ERROR OF 20\%, } \\
\text { THE SECURITY } \\
\text { PERFORMANCE } \\
\text { REMAINS } \\
\text { ABOVE } 90 \% \text {. }\end{array}$ \\
\hline $\begin{array}{l}\text { DEBAUCHE, } \\
\text { OLIVIER, ET } \\
\text { AL. [53] }\end{array}$ & $\begin{array}{l}\text { THREE NVIDIA } \\
\text { JETSON NANO } \\
\text { (472 } \\
\text { GFLOPS), } \\
\text { FOUR ODROID } \\
\text { N2 WITH } \\
\text { INTEGRATES A } \\
\text { QUAD-CORE, } \\
\text { 8-PORT } \\
\text { GIGABIT }\end{array}$ & $\begin{array}{l}\text { DEFINED A NEW } \\
\text { EDGE ARTIFICIAL } \\
\text { INTELLIGENCE OF } \\
\text { THING } \\
\text { ARCHITECTURE } \\
\text { THROUGH A } \\
\text { PARTNERSHIP } \\
\text { DEPLOYED IN THE } \\
\text { CLOUD WITH } \\
\text { MICROSERVICES. }\end{array}$ & $\begin{array}{l}\text { ACCURACY } \\
\text { DECREASES BY } \\
\text { AROUND 5\%. }\end{array}$ \\
\hline $\begin{array}{l}\text { CHEN, } \\
\text { JIENAN, ET } \\
\text { AL. [54] }\end{array}$ & $\begin{array}{l}\text { THE DEEP Q- } \\
\text { LEARNING } \\
\text { BASED } \\
\text { ALGORITHMS, } \\
\text { DEEP NEURAL } \\
\text { NETWORK, } \\
\text { MONTE } \\
\text { CARLO TREE } \\
\text { SEARCH } \\
\text { ALGORITHM }\end{array}$ & $\begin{array}{l}\text { PROPOSED AN } \\
\text { INTELLIGENT } \\
\text { RESOURCE } \\
\text { ALLOCATION } \\
\text { FRAMEWORK } \\
\text { (IRAF) }\end{array}$ & $\begin{array}{l}\text { IRAF DELIVERS } \\
59.27 \% \text { AND } \\
51.71 \% \\
\text { SPEEDUP ON- } \\
\text { LINE SERVICE } \\
\text { LATENCY. }\end{array}$ \\
\hline
\end{tabular}

\section{CONCLUSION}

In recent years, both academia and business companies have drawn the interest of the IoT. It is now an important component of our lives. It has the potential to link almost everything in our world to everything else. IoT systems are complex in design and have limited capacities for storage and retrieval. The integration of cloud computing with IoT would offer multiple advantages to numerous IoT applications. We have discussed in this article the state-ofthe-art cloud infrastructure, including cloud features, architecture, and benefits. The topic also centered on numerous technologies for IoT that would be expanded across the Cloud. Challenges of cloud IoT deployment and transparent problems are also discussed. In general, this paper's purpose was to include an overview to summarize up-to-date research contributions on cloud computing and the IoT and its applications in our environment and illustrate potential research directions and genuine concerns regarding the integration with the IoT of cloud computing.

\section{REFERENCES}

[1] M. A. Sadeeq, S. R. Zeebaree, R. Qashi, S. H. Ahmed, and K. Jacksi, "Internet of Things security: a survey," in 2018 International Conference on Advanced Science and Engineering (ICOASE), 2018, pp. 162-166.

[2] L. M. Haji, O. M. Ahmad, S. R. Zeebaree, H. I. Dino, R. R. Zebari, and H. M. Shukur, "Impact of cloud computing and internet of things on the future internet," Technology Reports of Kansai University, vol. 62, pp. 2179-2190, 2020.
S. Zeebaree and H. M. Yasin, "Arduino based remote controlling for home: power saving, security and protection," International Journal of Scientific \& Engineering Research, vol. 5, pp. 266-272, 2014.

A. I. Abdulla, A. S. Abdulraheem, A. A. Salih, M. A. Sadeeq, A. J. Ahmed, B. M. Ferzor, et al., "Internet of Things and Smart Home Security," Technol. Rep. Kansai Univ, vol. 62, pp. 2465-2476, 2020

A. A. Salih, S. R. Zeebaree, A. S. Abdulraheem, R. R. Zebari, M. A. Sadeeq, and O. M. Ahmed, "Evolution of Mobile Wireless Communication to 5G Revolution," Technology Reports of Kansai University, vol. 62, pp. 2139-2151, 2020.

A. Pichan, M. Lazarescu, and S. T. Soh, "A Logging Model for Enabling Digital Forensics in IoT, in an Inter-connected IoT, Cloud Eco-systems," in 2020 Fourth World Conference on Smart Trends in Systems, Security and Sustainability (WorldS4), 2020, pp. 478-483.

A. S. Abdulraheem, A. A. Salih, A. I. Abdulla, M. A. Sadeeq, N. O. Salim, H. Abdullah, et al., "Home automation system based on IoT," 2020.

S. I. Saleem, S. Zeebaree, D. Q. Zeebaree, and A. M. Abdulazeez, "Building Smart Cities Applications based on IoT Technologies: A Review," Technology Reports of Kansai University, vol. 62, pp. 1083-1092, 2020.

O. Alzakholi, H. Shukur, R. Zebari, S. Abas, and M. Sadeeq, "Comparison among cloud technologies and cloud performance," Journal of Applied Science and Technology Trends, vol. 1, pp. 40-47, 2020.

Z. N. Rashid, S. R. Zebari, K. H. Sharif, and K. Jacksi, "Distributed cloud computing and distributed parallel computing: A review," in 2018 International Conference on Advanced Science and Engineering (ICOASE), 2018, pp. 167-172.

Z. Ageed, M. R. Mahmood, M. Sadeeq, M. B. Abdulrazzaq, and $\mathrm{H}$. Dino, "Cloud computing resources impacts on heavyload parallel processing approaches," IOSR Journal of Computer Engineering (IOSR-JCE), vol. 22, pp. 30-41, 2020. R. Revathi, M. Suganya, and G. M. NR, "IoT based Cloud Integrated Smart Classroom for smart and a sustainable Campus," Procedia Computer Science, vol. 172, pp. 77-81, 2020

Z. S. Ageed, R. K. Ibrahim, and M. A. Sadeeq, "Unified Ontology Implementation of Cloud Computing for Distributed Systems," Current Journal of Applied Science and Technology, pp. 82-97, 2020.

P. Y. Abdullah, S. R. Zeebaree, H. M. Shukur, and K. Jacksi, "HRM system using cloud computing for Small and Medium Enterprises (SMEs)," Technology Reports of Kansai University, vol. 62, p. 04, 2020.

Z. N. Rashid, S. R. Zeebaree, and A. Shengul, "Design and analysis of proposed remote controlling distributed parallel computing system over the cloud," in 2019 International Conference on Advanced Science and Engineering (ICOASE), 2019, pp. 118-123.

M. Sadeeq, A. I. Abdulla, A. S. Abdulraheem, and Z. S. Ageed, "Impact of Electronic Commerce on Enterprise Business," Technol. Rep. Kansai Univ, vol. 62, pp. 23652378, 2020

A. M. Abdulazeez, S. R. Zeebaree, and M. A. Sadeeq, "Design and Implementation of Electronic Student Affairs System," Academic Journal of Nawroz University, vol. 7, pp. 66-73, 2018.

H. Shukur, S. Zeebaree, R. Zebari, D. Zeebaree, O. Ahmed, and A. Salih, "Cloud computing virtualization of resources allocation for distributed systems," Journal of Applied Science and Technology Trends, vol. 1, pp. 98-105, 2020.

L. M. Haji, S. Zeebaree, O. M. Ahmed, A. B. Sallow, K. Jacksi, and R. R. Zeabri, "Dynamic resource allocation for distributed systems and cloud computing," TEST Engineering \& Management, vol. 83, pp. 22417-22426, 2020.

A. Hosseinian-Far, M. Ramachandran, and C. L. Slack, "Emerging trends in cloud computing, big data, fog computing, IoT and smart living," in Technology for smart futures, ed: Springer, 2018, pp. 29-40.

J. Ren, H. Guo, C. Xu, and Y. Zhang, "Serving at the edge: A scalable IoT architecture based on transparent computing," IEEE Network, vol. 31, pp. 96-105, 2017. 

and the issues involved," in Proceedings of 2014 11th International Bhurban Conference on Applied Sciences \& Technology (IBCAST) Islamabad, Pakistan, 14th-18th January, 2014, 2014, pp. 414-419.

[23] R. Gravina, P. Alinia, H. Ghasemzadeh, and G. Fortino, "Multi-sensor fusion in body sensor networks: State-of-theart and research challenges," Information Fusion, vol. 35, pp. 68-80, 2017.

[24] P. Tan, H. Wu, P. Li, and H. Xu, "Teaching management system with applications of RFID and IoT technology," Education Sciences, vol. 8, p. 26, 2018.

[25] S. R. Zeebaree, K. Jacksi, and R. R. Zebari, "Impact analysis of SYN flood DDoS attack on HAProxy and NLB clusterbased web servers," Indones. J. Electr. Eng. Comput. Sci, vol. 19, pp. 510-517, 2020.

[26] C. Stergiou, K. E. Psannis, B.-G. Kim, and B. Gupta, "Secure integration of IoT and cloud computing," Future Generation Computer Systems, vol. 78, pp. 964-975, 2018.

[27] S. Kianoush, M. Raja, S. Savazzi, and S. Sigg, "A cloud-IoT platform for passive radio sensing: Challenges and application case studies," IEEE Internet of Things Journal, vol. 5, pp. 3624-3636, 2018.

[28] Z. N. Rashid, S. R. Zeebaree, and A. Sengur, "Novel Remote Parallel Processing Code-Breaker System via Cloud Computing."

[29] A. B. Sallow, M. Sadeeq, R. R. Zebari, M. B. Abdulrazzaq, M. R. Mahmood, H. M. Shukur, et al., "An Investigation for Mobile Malware Behavioral and Detection Techniques Based on Android Platform," IOSR Journal of Computer Engineering (IOSR-JCE), vol. 22, pp. 14-20.

[30] I. Mohiuddin and A. Almogren, "Workload aware VM consolidation method in edge/cloud computing for IoT applications," Journal of Parallel and Distributed Computing, vol. 123, pp. 204-214, 2019.

[31] S. S. Gill, S. Tuli, M. Xu, I. Singh, K. V. Singh, D. Lindsay, et al., "Transformative effects of IoT, Blockchain and Artificial Intelligence on cloud computing: Evolution, vision, trends and open challenges," Internet of Things, vol. 8, p. 100118,2019

[32] P. Y. Abdullah, S. R. Zeebaree, K. Jacksi, and R. R. Zeabri, "An hrm system for small and medium enterprises (sme) s based on cloud computing technology," International Journal of Research-GRANTHAALAYAH, vol. 8, pp. 56-64, 2020.

[33] S. Zeebaree, R. R. Zebari, K. Jacksi, and D. A. Hasan, "Security Approaches For Integrated Enterprise Systems Performance: A Review," Int. J. Sci. Technol. Res, vol. 8, 2019.

[34] L. a. Tawalbeh, F. Muheidat, M. Tawalbeh, and M. Quwaider, "IoT Privacy and security: Challenges and solutions," Applied Sciences, vol. 10, p. 4102, 2020.

[35] I. Mohiuddin, A. Almogren, M. Alrubaian, and M. AlQurishi, "Analysis of network issues and their impact on Cloud Storage," in 2019 2nd International Conference on Computer Applications \& Information Security (ICCAIS), 2019, pp. 1-4.

[36] S. K. Tayyaba, H. A. Khattak, A. Almogren, M. A. Shah, I. U. Din, I. Alkhalifa, et al., "5G vehicular network resource management for improving radio access through machine learning," IEEE Access, vol. 8, pp. 6792-6800, 2020.

[37] H. N. Almajed, A. S. Almogren, and A. Altameem, "A resilient smart body sensor network through pyramid interconnection," IEEE Access, vol. 7, pp. 51039-51046, 2019.

[38] H. Elazhary, "Internet of Things (IoT), mobile cloud, cloudlet, mobile IoT, IoT cloud, fog, mobile edge, and edge emerging computing paradigms: Disambiguation and research directions," Journal of Network and Computer Applications, vol. 128, pp. 105-140, 2019.

[39] A. Almogren, "An automated and intelligent Parkinson disease monitoring system using wearable computing and cloud technology," Cluster Computing, vol. 22, pp. 23092316, 2019.

[40] X. Xu, Q. Liu, Y. Luo, K. Peng, X. Zhang, S. Meng, et al., "A computation offloading method over big data for IoT-

enabled cloud-edge computing," Future Generation Computer Systems, vol. 95, pp. 522-533, 2019.

[41] K. Haseeb, N. Islam, A. Almogren, I. U. Din, H. N. Almajed, and N. Guizani, "Secret sharing-based energy-aware and multi-hop routing protocol for IoT based WSNs," IEEE Access, vol. 7, pp. 79980-79988, 2019.

[42] W.-Z. Zhang, I. A. Elgendy, M. Hammad, A. M. Iliyasu, X. $\mathrm{Du}$, M. Guizani, et al., "Secure and Optimized Load Balancing for Multi-Tier IoT and Edge-Cloud Computing Systems," IEEE Internet of Things Journal, 2020.

[43] K. Riad, T. Huang, and L. Ke, "A dynamic and hierarchical access control for IoT in multi-authority cloud storage," Journal of Network and Computer Applications, vol. 160, p. 102633, 2020.

[44] B. Mallikarjuna, "Feedback-Based Fuzzy Resource Management in IoT-Based-Cloud," International Journal of Fog Computing (IJFC), vol. 3, pp. 1-21, 2020.

[45] M. Anuradha, T. Jayasankar, N. Prakash, M. Y. Sikkandar, G. Hemalakshmi, C. Bharatiraja, et al., "IoT enabled cancer prediction system to enhance the authentication and security using cloud computing," Microprocessors and Microsystems, vol. 80, p. 103301, 2021.

[46] R. O. Aburukba, M. AliKarrar, T. Landolsi, and K. El-Fakih, "Scheduling Internet of Things requests to minimize latency in hybrid Fog-Cloud computing," Future Generation Computer Systems, vol. 111, pp. 539-551, 2020.

[47] B. Ali, M. A. Pasha, S. ul Islam, H. Song, and R. Buyya, "A volunteer supported fog computing environment for delaysensitive IoT applications," IEEE Internet of Things Journal, 2020.

[48] M. Wang and Q. Zhang, "Optimized data storage algorithm of IoT based on cloud computing in distributed system," Computer Communications, vol. 157, pp. 124-131, 2020.

[49] H. Fuentes and D. Mauricio, "Smart water consumption measurement system for houses using IoT and cloud computing," Environmental Monitoring and Assessment, vol. 192, pp. 1-16, 2020.

[50] M. Abdel-Basset, G. Manogaran, A. Gamal, and V. Chang, "A novel intelligent medical decision support model based on soft computing and IoT," IEEE Internet of Things Journal, vol. 7, pp. 4160-4170, 2019.

[51] A. Mavromatis, C. Colman-Meixner, A. P. Silva, X. Vasilakos, R. Nejabati, and D. Simeonidou, "A softwaredefined IoT device management framework for edge and cloud computing," IEEE Internet of Things Journal, vol. 7, pp. 1718-1735, 2019.

[52] L. Ding, Z. Wang, X. Wang, and D. Wu, "Security information transmission algorithms for IoT based on cloud computing," Computer Communications, vol. 155, pp. 32-39, 2020 .

[53] O. Debauche, S. Mahmoudi, S. A. Mahmoudi, P. Manneback, and F. Lebeau, "A new edge architecture for ai-iot services deployment," Procedia Computer Science, vol. 175, pp. 10$19,2020$.

[54] J. Chen, S. Chen, Q. Wang, B. Cao, G. Feng, and J. Hu, "iRAF: A deep reinforcement learning approach for collaborative mobile edge computing IoT networks," IEEE Internet of Things Journal, vol. 6, pp. 7011-7024, 2019.

[55] M. Abbasi, M. Yaghoobikia, M. Rafiee, A. Jolfaei, and M. R. Khosravi, "Efficient resource management and workload allocation in fog-cloud computing paradigm in IoT using learning classifier systems," Computer Communications, vol. 153, pp. 217-228, 2020 